\title{
Rates, causes, and types of readmissions after total joint arthroplasty
}

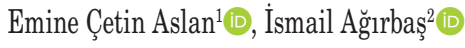 \\ ${ }^{1}$ Department of Health Management, Uşak University, Vocational School of Health Services, Uşak, Turkey \\ ${ }^{2}$ Department of Health Institutions Management, Ankara University, Faculty of Health Science, Ankara, Turkey
}

Received: November 13, 2018 Accepted: November 16, 2019 Published online: March 03, 2020

\begin{abstract}
Objectives: The aim of the study was to investigate the causes and rates of readmissions within 90 days after primary and revision knee and hip arthroplasties.

Patients and methods: A total of 1,516 patients (290 males, 1,226 females; mean age $64.7 \pm 10.5$ years; range, 21 to 91 years) who underwent primary total hip arthroplasty (THA), primary total knee arthroplasty (TKA), revision THA, and revision TKA between January 2013 and December 2014 were retrospectively analyzed. All readmissions within 90 days as of discharge dates of patients were analyzed and were categorized as planned readmissions related to the index admission, unplanned readmissions related to the index admission, planned readmissions unrelated to the index admission and unplanned readmissions unrelated to the index admission.

Results: Readmission rate in the overall of study group was found to be $5.61 \%$. This rate varied depending on the procedure applied, ranging between 2.35 and $6.74 \%$. Unplanned readmissions related to the index admission within 90 days consisted of $60.0 \%$ of total readmissions. A total of $82.0 \%$ of readmissions within 90 days was due to surgical reasons. Planned readmissions unrelated to the index admission within 90 days were also frequently seen (31.76\%). Totally $48.23 \%$ of total readmissions within 90 days occurred within the first 30 days. A total of $48.23 \%$ of the total readmissions and $58.82 \%$ of the readmissions which were unplanned and related to the index admission occurred within the first 30 days.

Conclusion: After knee and hip arthroplasties, readmissions occur due to various reasons. Therefore, it is of utmost importance to identify the readmission type in the evaluation of readmissions which may increase the effectiveness of precautions to be taken.
\end{abstract}

Keywords: Joint arthroplasty, readmission, readmission type.

Readmission is defined as the admission of a patient within a specific period of time after the index admission. ${ }^{[1]}$ There is a serious increase in the interest in readmissions recently. Among the reasons for this interest, it is possible to mention the following factors: the belief that readmissions are due to the lack of care quality. ${ }^{[2-4]}$ and unplanned readmissions are undesirable and stressful situations for patients, physicians, and the health system ${ }^{[5,6]}$ besides they are significant cost factors. ${ }^{[4,7,8]}$ It is highly important to use readmission rates, while evaluating the quality and performance of hospitals. ${ }^{[3,9]}$ Therefore, minimizing unnecessary readmissions decrease the health expenditures, while it provides a unique opportunity to servers and policymakers, since it enables health resources to be used more effectively and improves the care quality. ${ }^{[10]}$

Readmission is a complex phenomenon which occurs with the common effect of several factors, not only a single factor. ${ }^{[8,10-15]}$ Readmission types should be categorized to identify the reasons and to take necessary precautions for reducing the readmission rates. ${ }^{[16,17]}$ The points to take into consideration in grouping are that whether the readmission is determined during the discharge of the patient (planned) and whether it is about the index admission. Readmissions can be categorized under four different groups: planned readmissions related to the index admission; unplanned readmissions related to the index admission; planned readmissions unrelated to

Corresponding author: Emine Çetin Aslan, PhD. İzmir Bakırçay Üniversitesi, Sağlık Bilimleri Fakültesi, Sağlık Yönetimi Bölümü, 35665 Menemen, İzmir, Türkiye. e-mail: cetinemine@gmail.com 
the index admission; and unplanned readmissions unrelated to the index admission. ${ }^{[18]}$

Using readmissions as the indicator of the care quality is seriously criticized, as hospitals have not enough power to control all reasons for readmission. However, the readmission rate is a criterion which is commonly used in the evaluation of the joint arthroplasty results. ${ }^{[19]}$ Readmission rates may vary depending on whether the surgery is primary or revision and also arthroplasty is applied to knee or hip. These rates can be also affected by certain variables such as the index admission diagnosis, time period that the readmissions are monitored, regarded readmission type, and the characteristics of patient population in the study.

The aim of this study was to identify the readmission rates, readmission types, and readmission reasons for the patients who underwent join arthroplasty in a tertiary hospital within 90 days in the period of following the discharge. Our study is original, as it, for the first time, evaluates the primary and revision knee and hip arthroplasties, different readmission types, and the readmission within $7,30,60$, and 90 days as combined in this patient population.

\section{PATIENTS AND METHODS}

This retrospective cohort study included patients who were admitted Ankara Numune Training and Research Hospital for primary total hip arthroplasty (THA), primary total knee arthroplasty (TKA), revision THA, and revision TKA between January 2013 and December 2014. No sampling method was used and all the patients who met the criteria were included in the study. Readmission was defined as the readmission of a patient after the discharge following the index admission for any reasons to the hospital where knee or hip arthroplasty was done. To calculate the readmission rates, the number of the readmitted patients was used, but not the number of readmissions. The time period for readmission was 90 days. Seven-, $30-$, and 60-day periods were also analyzed to examine the features of readmissions.

Exclusion criteria were as follows: referral from an external clinic in the index admission in which the surgical procedure was performed or transferring the patients to another clinic after the surgical procedure; discharge against medical advice and deaths during the index admission period. Quadruplet grouping offered by the American Hospital Association (2011) ${ }^{[18]}$ was used for classifying the readmissions according to the types: readmissions planned and related to the index admission, readmissions unplanned and related to the index admission, readmissions planned and unrelated to the index admission, readmissions unplanned and unrelated to the index admission. Among these types, readmissions planned and unrelated to index admission, as evident from its name, were not related to the treatment in index admission. However, in all-cause readmissions studies, these readmissions should also be included in calculation and grouped appropriately. For instance, admission of a patient who underwent TKA in index admission and planning another TKA for the other joint after one month was a readmission planned and unrelated to index admission. To identify the readmission types, main diagnoses of readmissions classified according to ICD 10-AM (International Statistical Classification of Diseases and Related Health Problems, $10^{\text {th }}$ Revision, Australian Modification) and the information in the index admission and readmission report of patients were considered. ${ }^{[20]}$

A written informed consent was obtained from each patient. The study protocol was approved by the Uşak University Social and Humanities Scientific Research and Publication Ethics Committee. The study was conducted in accordance with the principles of the Declaration of Helsinki. Data of the patients were obtained from the hospital information system. The admissions within this study period due to any of total primary and revision knee and hip arthroplasties were initially determined in data collection stage. A total of 1,527 patients were found through the scanning with this method. Two patients who died during the index admission, eight patients who were discharged against medical advice, and one patient who was transferred from another clinic were excluded from the study. Finally, a total of 1,516 patients (290 males, 1,226 females; mean age $64.7 \pm 10.5$ years; range, 21 to 91 years) were included in the study.

\section{Statistical analysis}

Statistical analysis was performed using the IBM SPSS version 23.0 software (IBM Corp., Armonk, NY, USA). Categorical variables were expressed in number and frequency, while continuous variables were expressed in mean \pm standard deviation (SD). The Kolmogorov-Smirnov and ShapiroWilk tests were used to determine whether the data showed a normal distribution between the readmitted and non-readmitted patients. Continuous numerical and discrete numerical data in the independent groups were analyzed using 


\begin{tabular}{|c|c|c|c|c|c|}
\hline \multirow[b]{3}{*}{ Procedure type } & \multicolumn{2}{|c|}{$\begin{array}{l}\text { ABLE } 1 \\
\text { laracteristics }\end{array}$} & \multirow{3}{*}{$\frac{\text { Age }}{\text { Mean } \pm \text { SD }}$} & \multirow{2}{*}{\multicolumn{2}{|c|}{ Total }} \\
\hline & \multicolumn{2}{|c|}{ Gender } & & & \\
\hline & $\mathrm{n}$ & $\%$ & & $\mathrm{n}$ & $\%$ \\
\hline \multicolumn{6}{|c|}{ Total hip arthroplasty, primary } \\
\hline Female & 196 & 67 & \multirow{2}{*}{$58.7 \pm 13.8$} & \multirow{2}{*}{292} & \multirow{2}{*}{19.26} \\
\hline Male & 96 & 33 & & & \\
\hline \multicolumn{6}{|c|}{ Total knee arthroplasty, primary } \\
\hline Female & 907 & 86 & \multirow{2}{*}{$66.0 \pm 8.4$} & \multirow{2}{*}{1050} & \multirow{2}{*}{69.26} \\
\hline Male & 143 & 14 & & & \\
\hline \multicolumn{6}{|c|}{ Total hip arthroplasty, revision } \\
\hline Female & 54 & 64 & \multirow{2}{*}{$65.6 \pm 13.6$} & \multirow{2}{*}{85} & \multirow{2}{*}{5.61} \\
\hline Male & 31 & 36 & & & \\
\hline \multicolumn{6}{|c|}{ Total knee arthroplasty, revision } \\
\hline Female & 69 & 78 & \multirow{2}{*}{$68.0 \pm 9.2$} & \multirow{2}{*}{89} & \multirow{2}{*}{5.87} \\
\hline Male & 20 & 22 & & & \\
\hline
\end{tabular}

the Mann-Whitney U test. Categorical variables for readmitted and non-readmitted patients were analyzed using the Pearson chi-square test. A $p$ value of $<0.05$ was considered statistically significant.

\section{RESULTS}

Of the patients, those who underwent TKA were older than those who underwent THA, while revision patients were older than primary patients. Demographic characteristics of the patients are shown in Table 1.

The rates and types of the readmissions according to the procedures are summarized in Table 2 . Accordingly, 85 patients were readmitted in the study group within 90 days and the readmission rate was
$5.61 \%$. A total of 76 patients in the study group were readmitted for once, eight patients for twice, and one patient for thrice. Therefore, the total number of readmissions was 95 . The readmission rates were as follows: $6.74 \%$ for revision TKAs, $6.16 \%$ for primary THAs, $5.62 \%$ for primary TKAs, and $2.35 \%$ for revision THAs. The readmission rate for THAs in primary procedures was higher than the TKAs in primary procedures, which was vice versa in revision procedures.

The most frequent readmission type was the readmission that unplanned and related to the index admission. More interestingly, this readmission type was higher in revision procedures. Four of six readmissions in the revision knee arthroplasty

\begin{tabular}{|c|c|c|c|c|c|c|c|c|c|c|}
\hline Distrib & of & missi & B1 & Readm & n ty & cedu & & & & \\
\hline & \multicolumn{4}{|c|}{ Unrelated } & \multicolumn{4}{|c|}{ Related } & & \\
\hline & \multicolumn{2}{|c|}{ Planned } & \multicolumn{2}{|c|}{ Unplanned } & \multicolumn{2}{|c|}{ Planned } & \multicolumn{2}{|c|}{ Unplanned } & \multicolumn{2}{|c|}{ Total } \\
\hline & $\mathrm{n}$ & $\mathrm{RR}$ & $\mathrm{n}$ & $\mathrm{RR}$ & $\mathrm{n}$ & $\mathrm{RR}$ & $\mathrm{n}$ & $\mathrm{RR}$ & $\mathrm{n}$ & $\mathrm{RR}$ \\
\hline Total hip arthroplasty, primary $(n=292)$ & 5 & 1.10 & 3 & 1.03 & 0 & 0.00 & 10 & 3.42 & 18 & 6.16 \\
\hline Total knee arthroplasty, primary $(n=1050)$ & 21 & 2.00 & 2 & 0.19 & 1 & 0.09 & 35 & 3.33 & 59 & 5.62 \\
\hline Total hip arthroplasty, revision $(\mathrm{n}=85)$ & 0 & 0.00 & 0 & 0.00 & 0 & 0.00 & 2 & 2.35 & 2 & 2.35 \\
\hline Total knee arthroplasty, revision $(n=89)$ & 1 & 1.12 & 1 & 1.12 & 0 & 0.00 & 4 & 4.49 & 6 & 6.74 \\
\hline Total $(n=1,516)$ & 27 & 1.78 & 6 & 0.40 & 1 & 0.07 & 51 & 3.36 & 85 & 5.61 \\
\hline
\end{tabular}




\begin{tabular}{|c|c|c|c|c|c|c|c|c|}
\hline \multicolumn{9}{|c|}{$\begin{array}{l}\text { TABLE } 3 \\
\text { Readmission types according to the time periods }\end{array}$} \\
\hline \multirow[b]{2}{*}{ Readmission types } & \multicolumn{2}{|c|}{ 0-7 day } & \multicolumn{2}{|c|}{ 0-30 day } & \multicolumn{2}{|c|}{$0-60$ day } & \multicolumn{2}{|c|}{$0-90$ day } \\
\hline & $\mathrm{n}$ & $\%$ & $\mathrm{n}$ & $\%$ & $\mathrm{n}$ & $\%$ & $\mathrm{n}$ & $\%$ \\
\hline Unplanned and related to initial admission & 11 & 0.73 & 30 & 1.98 & 48 & 3.17 & 51 & 3.36 \\
\hline Planned and unrelated to initial admission & 2 & 0.13 & 8 & 0.53 & 19 & 1.25 & 27 & 1.78 \\
\hline Unplanned and unrelated to initial admission & 1 & 0.07 & 2 & 0.13 & 5 & 0.33 & 6 & 0.40 \\
\hline Planned and related to initial admission & 0 & 0.00 & 1 & 0.07 & 1 & 0.07 & 1 & 0.07 \\
\hline Total readmission & 14 & 0.92 & 41 & 2.70 & 73 & 4.82 & 85 & 5.61 \\
\hline Total admission & 1,516 & & 1,516 & & 1,516 & & 1,516 & \\
\hline
\end{tabular}

and both of the two readmissions in the revision hip arthroplasty were the readmissions unplanned and related to the index admission. Another most frequent readmission type in the study group was the readmission that planned and unrelated to the index admission. Most of the readmissions in this group occurred with the diagnosis of gonarthrosis or coxarthrosis with the aim of placing another joint prosthesis. The readmission rate accounted for $1.78 \%$ of readmission in the overall study group, constituting almost one-third $(31.76 \%)$ of the total readmissions. Readmissions planned and unrelated to the index admission were more frequently observed in the primary procedures than revision procedures. Five $(27.78 \%)$ of 18 readmissions in primary THAs and $21(36 \%)$ of 59 readmissions after primary TKAs were the readmissions planned and unrelated to the index admission.

Readmission rates for the general study group according to readmissions types within $7,30,60$, and
90 days were analyzed in Table 3 . The readmission rates increased in other readmission types, except for the readmissions planned and related to the index admission, as the time period extended. Nearly half of the total readmissions (48.24\%) occurred within 30 days (Table 4). The time period that the readmissions types occurred varied. A significant part of the readmissions unplanned and related to the index admissions occurred in 0 to 7 and 0 to 30 days $(21.57 \%$ and $58.82 \%$, respectively). However, unrelated and planned readmissions increased after 30 days (19 of 27 readmissions occurred after 30 days), as readmissions unplanned and related to index admission due to such reasons as embolism, acute renal failure, anemia related to the joint prosthesis performed in the index admission occurred in early periods. However, readmissions planned and unrelated to index admission due to such reasons as a prosthesis placement to another joint and cataract occurred in late periods.

\begin{tabular}{|c|c|c|c|c|c|c|c|c|}
\hline \multirow[b]{3}{*}{ Readmission types } & \multirow{2}{*}{\multicolumn{2}{|c|}{$\begin{array}{c}\text { TABLE } 4 \\
\text { tion of readm } \\
0-7 \text { day }\end{array}$}} & \multirow{2}{*}{\multicolumn{2}{|c|}{ 0-30 day }} & \multirow{2}{*}{\multicolumn{2}{|c|}{$0-60$ day }} & \multirow{2}{*}{\multicolumn{2}{|c|}{ 0-90 day }} \\
\hline & & & & & & & & \\
\hline & $\mathrm{n}$ & $\%$ & $\mathrm{n}$ & $\%$ & $\mathrm{n}$ & $\%$ & $\mathrm{n}$ & $\%$ \\
\hline Unplanned and related to initial admission & 11 & 78.57 & 30 & 73.17 & 48 & 65.75 & 51 & 60.00 \\
\hline$\%$ & 21.57 & & 58.82 & & 94.12 & & 100.00 & \\
\hline Planned and unrelated to initial admission & 2 & 14.29 & 8 & 19.51 & 19 & 26.03 & 27 & 31.76 \\
\hline$\%$ & 7.41 & & 29.63 & & 70.37 & & 100.00 & \\
\hline Unplanned and unrelated to initial admission & 1 & 7.14 & 2 & 4.88 & 5 & 6.85 & 6 & 7.06 \\
\hline$\%$ & 16.67 & & 33.33 & & 83.33 & & 100.00 & \\
\hline Planned and related to initial admission & 0 & 0.00 & 1 & 2.44 & 1 & 1.37 & 1 & 1.18 \\
\hline$\%$ & 0.00 & & 100.00 & & 100.00 & & 100.00 & \\
\hline Total readmission & 14 & 100.00 & 41 & 100.00 & 73 & 100.00 & 85 & 100.00 \\
\hline$\%$ & 16.47 & & 48.24 & & 85.88 & & 100.00 & \\
\hline
\end{tabular}




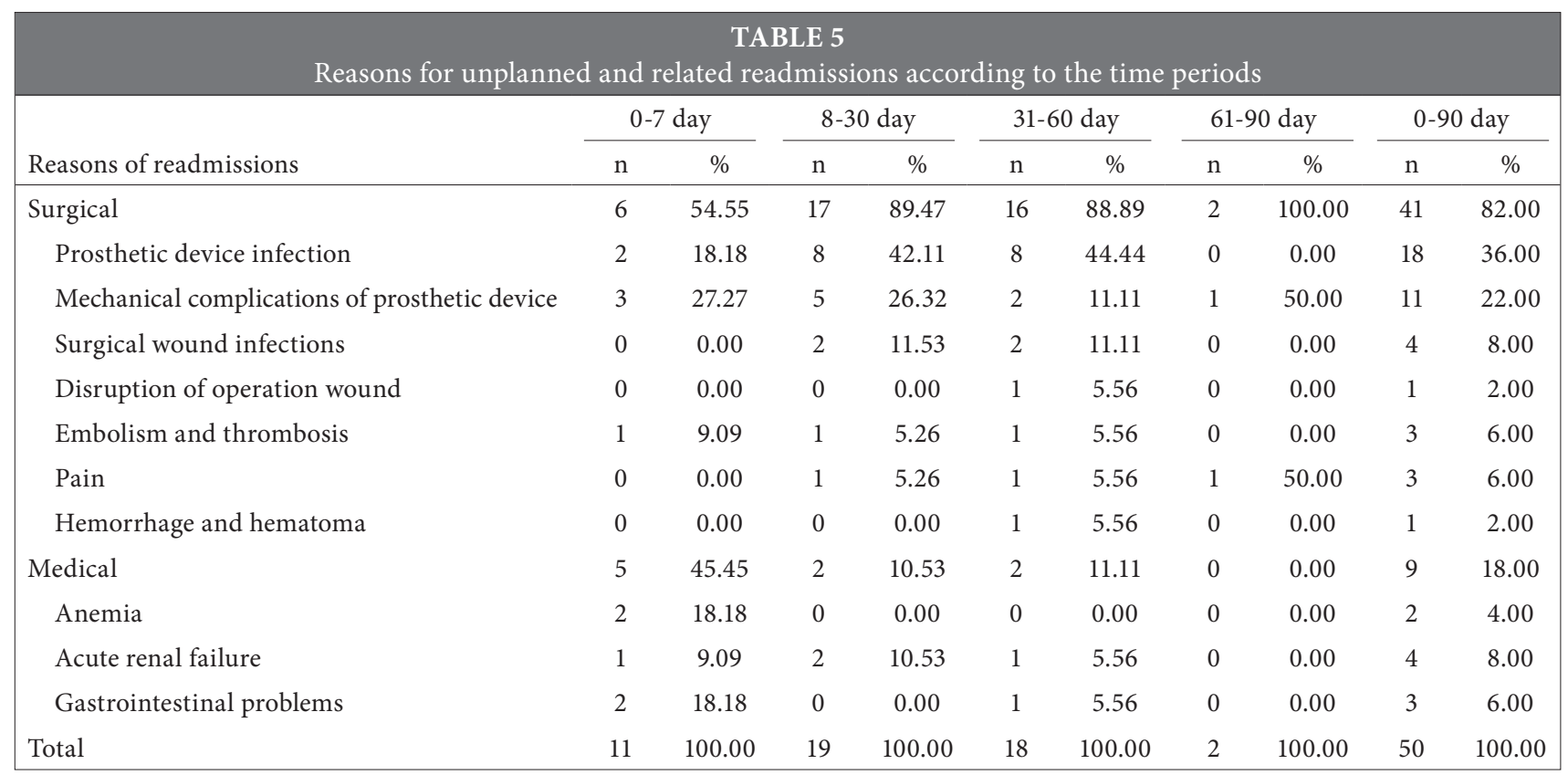

Table 5 shows the causes and time to occur of readmissions unplanned and related to the index admission are analyzed. In general, surgical based readmissions are more frequently seen compared to medical-based readmissions in all time periods and this feature became clearer as the time extended.

\begin{tabular}{|c|c|c|c|c|c|c|}
\hline \multicolumn{7}{|c|}{$\begin{array}{c}\text { TABLE } 6 \\
\text { Comparison of the readmitted and non-readmitted }\end{array}$} \\
\hline \multirow[b]{2}{*}{ Variable } & \multirow{2}{*}{$\frac{\text { Non-readmitted }}{\mathrm{n}}$} & \multirow{2}{*}{$\frac{\text { Readmitted }}{\mathrm{n}}$} & \multirow[b]{2}{*}{$\mathrm{n}$} & \multirow{2}{*}{$\frac{\text { Readmission rate }}{\%}$} & \multirow[b]{2}{*}{ Chi-square } & \multirow[b]{2}{*}{$p^{*}$} \\
\hline & & & & & & \\
\hline \multicolumn{7}{|l|}{ Gender } \\
\hline Female & 1187 & 39 & 1226 & 3.18 & & \\
\hline Male & 279 & 11 & 290 & 3.79 & 0.117 & 0.732 \\
\hline Total & 1466 & 50 & 1516 & 3.30 & & \\
\hline \multicolumn{7}{|c|}{ Age (With grouping) } \\
\hline$<65$ & 672 & 18 & 690 & 2.61 & & \\
\hline$\geq 65$ & 793 & 32 & 825 & 3.88 & 1.522 & 0.217 \\
\hline Total & 1465 & 50 & 1515 & 3.30 & & \\
\hline \multicolumn{7}{|c|}{ Complication } \\
\hline No & 1096 & 32 & 1128 & 2.84 & & \\
\hline Yes & 370 & 18 & 388 & 4.64 & 2.402 & 0.121 \\
\hline Total & 1466 & 50 & 1516 & 3.30 & & \\
\hline \multicolumn{7}{|c|}{ Intensive care unit } \\
\hline No & 1432 & 48 & 1480 & 3.24 & & \\
\hline Yes & 34 & 2 & 36 & 5.56 & 0.087 & 0.335 \\
\hline Total & 1466 & 50 & 1516 & 3.30 & & \\
\hline \multicolumn{7}{|c|}{ Comorbidity } \\
\hline No & 256 & 6 & 262 & 2.29 & & \\
\hline Yes & 1210 & 44 & 1254 & 3.51 & 0.663 & 0.415 \\
\hline Total & 1466 & 50 & 1516 & 3.30 & & \\
\hline
\end{tabular}




\begin{tabular}{|c|c|c|c|c|c|c|}
\hline \multirow[b]{2}{*}{ Variable } & of the readmitted and non- & $\begin{array}{l}\text { BLE } 7 \\
\text { nitted }\end{array}$ & ts in terms & continuous va & ables & \\
\hline & Readmitted/non-readmitted & $\mathrm{n}$ & Mean rank & Sum of ranks & $\mathrm{U}$ & $p$ \\
\hline \multirow{2}{*}{ Age (No grouping) } & Non-readmitted & 1,465 & 755.53 & $1,106,855.00$ & \multirow{2}{*}{$33,010.00$} & \multirow{2}{*}{0.168} \\
\hline & Readmitted & 50 & 830.30 & $41,515.00$ & & \\
\hline \multirow{2}{*}{ Length of hospital stay } & Non-readmitted & 1,466 & 752.94 & $1,103,813.50$ & \multirow{2}{*}{$28,502.50$} & \multirow{2}{*}{$0.007^{\star}$} \\
\hline & Readmitted & 50 & 921.45 & $46,072.50$ & & \\
\hline
\end{tabular}

Medical-based readmissions were mostly seen in the early stages of time period, particularly within the first seven days. The rate of surgical and medical-based readmissions within the first seven days was close to each other (55\% vs. $45 \%$, respectively). However, this rate was approximately nine times within 31 to 60 -day period. Two most frequently observed factors in the surgical based readmissions were the prosthesis infections (18 readmissions and 36\%) and mechanic complications of the prostheses (11 readmissions and $22 \%$, respectively). The problems (infection and mechanic complication) based on the prosthesis constituted $70.73 \%$ of surgical based readmissions and $58.0 \%$ of all readmissions.

Age, gender, comorbidities, complications, the length of stay in the intensive care unit and hospital in the index admission were analyzed to assess whether they had an effect on readmissions. It was found that none of the analyzed data groups indicated a normal distribution $(\mathrm{p}<0.05)$.

Whether the categorical variables (gender, age, complication, intensive care unit, and comorbidities) related to readmitted and non-admitted patients varied between readmitted and non-admitted patients were analyzed (Table 6). The readmission rates were higher in male patients, the patients who were $\geq 65$ years, who developed a complication during the index admission, received intensive care treatment, and had a comorbidity compared to the opposite group. However, this high rate was not found to be statistically significant.

Age and length of hospital stay were used to compare the continuous variables from the index admission. When age variable in the index admission was analyzed, it was found that readmitted patients were older than non-readmitted ones. However, the difference was not found to be statistically significant $(U=330,110.00 ; p>0.05)$. When the length of the hospital stay in the index admission was analyzed, readmitted patients stayed longer than non-readmitted ones, indicating a statistical significance $(U=28,502.50$; $\mathrm{p}<0.05$ ) (Table 7).

\section{DISCUSSION}

The present study is one of the limited number of studies which evaluates total and revision knee and hip arthroplasties together in the same patient group. ${ }^{[21]}$ Selected different time periods and readmission types in measuring readmissions were also evaluated as combined, which renders this study original.

Readmission rates within 90 days after the joint arthroplasty differed significantly according to the joint type where the procedure was applied to. The readmission rate (6.16\%) in THAs was slightly higher than the rate in TKAs (5.62\%) in primary procedures. However, when the readmission rates of unplanned and related to the index admission, a better indicator to indicate the care quality, were compared and we observed an increase in the difference $(3.42 \%$ and $3.33 \%$, respectively). The values between $3.0 \%$ and $4.70 \%$ have been reported in the literature for joint procedures and the same time periods. ${ }^{[2,22,23]}$ The compared study findings indicate that the readmission rates may vary from one study to another one. In addition, we observed that readmission rates based upon the THAs were higher than the rates based upon the TKAs. This difference is thought to be related to the absence of readmission, due to the frequently observed joint stiffness after the TKAs. As there was no readmission in our study due to joint stiffness. Expert opinions confirm that readmission is not common in the Turkish population due to joint stiffness. It is even an outpatient treatment. However, since this study is the only study that we have obtained to date, which analyzes readmissions on TKAs and THAs in the Turkish population, it would not be possible to compare it with the literature findings.

On contrary to the primary procedures, readmission rates in revision procedures were found 
to be $6.74 \%$ for knee revision arthroplasty and $2.35 \%$ for hip revision arthroplasty and knee revision arthroplasty was almost two times more than the hip arthroplasty. These rates were $4.49 \%$ and $2.35 \%$ in the knee and hip revision arthroplasties, respectively in terms of readmissions unplanned and related to the index admission. In addition, although the readmission rate after revision TKA was higher than the readmission rate after the primary procedure (TKA; primary procedure: $3.33 \%$, revision: $4.49 \%$ ), it was the opposite in the THA (THA; primary procedure: $3.42 \%$, revision: $2.35 \%$ ), as we compared the joint procedures. The revision procedures have higher readmission rates, as they are more traumatic, more difficult for the physicians and necessitate more resource for the hospital. However, lower readmission rate after the revision THA cannot been explained yet. Readmission rates in 90 days after revision THA were found in different values such as $7.9 \%,{ }^{[24]} 13 \%{ }^{[5]}$ and $21.7 \%{ }^{[21]}$ However, the readmission rates after revision TKA for the same period were $6.4 \%^{[24]}$ and $23.1 \%^{[21]}$ in the literature.

One of the most common readmission types after TKAs and THAs is the readmissions planned and unrelated to the index admissions. Most of these readmissions are due to the insertion of a prosthesis in another joint of the patient. Indeed, these readmissions are the consequences of twostage procedure rather than simultaneous bilateral arthroplasty. In our study, readmissions planned and unrelated to index admission constituted $36 \%$ of the total readmissions after primary knee arthroplasties (21/59 readmissions), $28 \%$ of primary hip arthroplasties (5/18 readmissions), and $32 \%$ of the total readmissions (27/85 readmissions). Zmistowski et al. $^{[23]}$ found that $15.3 \%$ of all readmissions were planned readmissions. Readmissions planned and unrelated to index admissions were not found to be associated with treatment in index admission. Yet, they can be monitored with financial concerns. ${ }^{[25]}$

Another important factor that affects the readmission rates is the analyzed time period. It is obvious that the readmissions within 30 days after the discharge are often regarded in the literature as the time period for readmissions. However, the index admissions and the related and unplanned readmissions within 30 days form $58.82 \%$ of the total readmissions within 90 days. In other words, regarding the readmission time period in knee and hip arthroplasties as 30 days refers to taking more than $40 \%$ of the readmissions unplanned and related to index admissions out of context. This rate has been reported in the literature ranging between 50 and $71 \% \cdot{ }^{[23,26]}$

The share of surgical reasons was higher than the medical reasons in all of the analyzed time period in the factors, leading to the readmission in the study group. The share of surgical reasons in readmissions within 30 days was found to be $89.0 \%$, and the share of surgical reasons in readmissions within 90 days was found to be $82.0 \%$. These findings were reported in the literature ranging from 40 to $62 \%{ }^{[5,23]}$ for 30 days and 66 to $75 \%{ }^{[23,27]}$ for 90 days. In our study, the most common reason for readmissions for all of the analyzed time periods was the surgical site infection (sum of prosthetic device infection, mechanical complications of prosthetic device and surgical wound infections). Our findings are consistent with the literature..$^{[2,23,27,28]}$

Age and gender are also the frequently examined variables in terms of readmission risk factors in the literature. In our study, the readmission rate $(3.88 \%)$ of the patients aged $\geq 65$ was higher than the readmission rate $(2.61 \%)$ of those who were in the $0-64$ age group. This is also consistent with the literature. ${ }^{[19,23,27]}$ There are also studies reporting that age of the patient is not a determinant factor for the readmission risk. ${ }^{[28,29]}$ In our study, gender was not found to be a risk factor. However, the readmission rate of males was higher than the rate of females. Although gender was indicated as a significant risk factor for readmissions in some studies in the literature, ${ }^{[5,23,28-31]}$ it was not indicated as a risk factor in many others. ${ }^{[5,22,27-30]}$

Furthermore, there is a close relationship between the complications developed after the procedure and the readmissions. Indeed, the reason for the readmissions related to the index admission is the procedure-based complications developed after discharge. Although the complications developed during the index admission do not directly lead to the readmission, these complications increase the readmission possibility for the patient. Glance et al. ${ }^{[32]}$ examined the readmissions after serious surgical procedures and found that the most important predictor of readmissions was the complication development. According to these findings, readmission rate for the patients who developed complication after discharge was $78.3 \%$. This rate was $12.3 \%$ for the patients who developed a complication during the hospitalization. Finally, this rate was $4.8 \%$ for the patients who did not develop any complication. In another study, Morris et al. ${ }^{[33]}$ found that the complications occurred during the index admission increased the readmission risk 
by $18.3 \%$, and complications after discharge increased the same risk by $58.9 \%$. In our study, the readmission rate for the patients who developed complication was higher as $63 \%$ than the rate of the patients who were not readmitted ( $4.64 \%$ vs. $2.84 \%$, respectively). Similarly, the readmission rate $(5.56 \%)$ for the patients who stayed in the intensive care unit due to lifethreatening complications occurred during the index admission was higher than the rate of (3.24\%) patients who did not.

In the comparison for readmitted and nonreadmitted patients' length of hospital stay was the only variable which was statistically significant. In our study, the length of hospital stay of readmitted patients was higher than non-readmitted. The mean hospitalization time varied from 2.9 to 6 days in previous studies in the literature. ${ }^{[2,19,30,33]}$ In our study, the length of hospital stay was very long for both admitted and non-admitted patients, compared to other study findings. Prolonged hospitalization period may affect the readmission rates, particularly due to medical reasons. According to Parvizi et al., ${ }^{[34]} 90 \%$ of dangerous complications developed within four days after the surgical procedure. In the literature, delaying the discharge for three days after the operation was associated with complications occurred during the hospital stay. ${ }^{[2,35]}$ As the main reason for higher share of surgical reasons in readmissions than other studies, prolonged hospitalization period in our study than other studies is thought to have a great role.

Nonetheless, there are some limitations to this study. First, the study was carried out in a single center. Therefore, it was unable to evaluate whether there was any readmission in other institutions. Second, this study has a retrospective design and all data in the records are considered complete and accurate. The readmission rates found in the study were lower than other study findings investigating the readmissions after TKA and THA. Low readmission rate was a highly positive finding. However, the share of this limitations cannot be appreciated as the reason for low readmission rates.

In conclusion, the most common readmission type after TKA and THA are those unplanned and related to the index admission throughout the study. Most of these readmissions were due to the surgical reasons. Mechanical and infection-related prosthetic complications were responsible for more than half of the total readmissions. Therefore, most of the readmissions after TKA and THA were found to be associated with the treatment in index admission. Based on these findings, certain measures to be taken during the index admission may reduce the readmission rate. However, it is not possible to completely eliminate readmissions due to factors such as age, gender, and comorbidity. Also, the readmissions planned and unrelated to the index admissions are also common after TKA and THA. Most of these readmissions are due to arthroplasty of another joint. These readmissions are not associated to the care quality, but with treatment planning.

\section{Declaration of conflicting interests}

The authors declared no conflicts of interest with respect to the authorship and/or publication of this article.

\section{Funding}

The authors received no financial support for the research and/or authorship of this article.

\section{REFERENCES}

1. Jencks SF, Williams MV, Coleman EA. Rehospitalizations among patients in the Medicare fee-for-service program. N Engl J Med 2009;360:1418-28.

2. Avram V, Petruccelli D, Winemaker M, de Beer J. Total joint arthroplasty readmission rates and reasons for 30-day hospital readmission. J Arthroplasty 2014;29:465-8.

3. Clement RC, Kheir MM, Derman PB, Flynn DN, Speck RM, Levin LS, et al. What are the economic consequences of unplanned readmissions after TKA? Clin Orthop Relat Res 2014;472:3134-41.

4. Bianco A, Molè A, Nobile CG, Di Giuseppe G, Pileggi C, Angelillo IF. Hospital readmission prevalence and analysis of those potentially avoidable in southern Italy. PLoS One 2012;7:e48263.

5. Schairer WW, Vail TP, Bozic KJ. What are the rates and causes of hospital readmission after total knee arthroplasty? Clin Orthop Relat Res 2014;472:181-7.

6. Steventon A, Krumholz H. Does US health reform reduce hospital readmission rates? BMJ 2014;348:g2641.

7. Lagoe RJ, Nanno D, Luziani M. Clinical identification of patients readmitted to hospitals: why patients return. BMC Res Notes 2013;6:419.

8. Stone, J, Hoffman, G. Medicare hospital readmissions: Issues and policy options. Medicare: Background, Benefits and Issues 2011;123-50

9. Westert GP, Lagoe RJ, Keskimäki I, Leyland A, Murphy M. An international study of hospital readmissions and related utilization in Europe and the USA. Health Policy. 2002;61:269-78.

10. Minott J. Reducing Hospital Readmissions. AcademyHealtht 2008. Available at: https://www.academyhealth.org [Accessed: November, 2008]

11. Blunt I, Bardsley M, Grove A, Clarke A. Classifying emergency 30-day readmissions in England using routine hospital data 2004-2010: what is the scope for reduction? Emerg Med J 2015;32:44-50. 
12. Canadian Institute for Health Information. All-Cause Readmission to Acute Care and Return to the Emergency Department. Heal Syst Perform; 2012. Available at: https:// secure.cihi.ca/free_products/Readmission_to_acutecare_ en.pdf [Accessed: September 12, 2018]

13. Agency for Healthcare Research and Quality. Introduction to the HCUP Nationwide Readmissions Database (NRD). Available at: https://www.hcup-us.ahrq.gov/db/nation/nrd/ Introduction_NRD_2010-2014.pdf. [Accessed: September 17, 2018]

14. Barrett ML, Wier LM, Jiang J, Steiner CA. All-Cause Readmissions by Payer and Age, 2009-2013. HCUP Stat $\mathrm{Br} \# 199$. Available at: http://www.ncbi.nlm.nih.gov/ pubmed/26866240. [Accessed: December, 2015]

15. Hines AL, Barrett ML, Jiang J, Steiner CA. Conditions With the Largest Number of Adult Hospital Readmissions by Payer. Healthc Cost Util Proj 2014;363:1-10.

16. Southern DA, Ngo J, Martin BJ, Galbraith PD, Knudtson ML, Ghali WA, et al. Characterizing types of readmission after acute coronary syndrome hospitalization: implications for quality reporting. J Am Heart Assoc 2014;3:e001046.

17. Friedman B, Basu J. The rate and cost of hospital readmissions for preventable conditions. Med Care Res Rev 2004;61:225-40.

18. AssociAtion AH. Examining the Drivers of Readmissions and Reducing Unnecessary Readmissions for Better Patient Care PPT Deck. TrendWaTch; 2011. Available at: https:// www.aha.org/guidesreports/2011-09-14-examining-driversreadmissions-and-reducing-unnecessary-readmissions. [Accessed: September 17, 2018]

19. Paxton EW, Inacio MC, Singh JA, Love R, Bini SA, Namba RS. Are There Modifiable Risk Factors for Hospital Readmission After Total Hip Arthroplasty in a US Healthcare System? Clin Orthop Relat Res 2015;473:3446-55.

20. National Centre for Classification in Health ( $\mathrm{NCCH})$. Australian Coding Standards. In: The International Statistical Classification of Diseases and Health Related Problems, Tenth Revision, Australian Modification (ICD10-AM). 5th ed. Sydney: NCCH; 2006.

21. Nichols CI, Vose JG. Clinical outcomes and costs within 90 days of primary or revision total joint arthroplasty. J Arthroplasty 2016;31:1400-6.

22. Saucedo JM, Marecek GS, Wanke TR, Lee J, Stulberg SD, Puri L. Understanding readmission after primary total hip and knee arthroplasty: who's at risk? J Arthroplasty 2014;29:256-60.

23. Zmistowski B, Restrepo C, Hess J, Adibi D, Cangoz S, Parvizi J. Unplanned readmission after total joint arthroplasty: rates, reasons, and risk factors. J Bone Joint Surg [Am] 2013;95:1869-76.

24. Keswani A, Lovy AJ, Robinson J, Levy R, Chen D, Moucha CS. Risk Factors Predict Increased Length of Stay and Readmission Rates in Revision Joint Arthroplasty. J Arthroplasty 2016;31:603-8.

25. Kristensen SR, Bech M, Quentin W. A roadmap for comparing readmission policies with application to Denmark, England, Germany and the United States. Health Policy 2015;119:264-73.

26. Cram P, Lu X, Kaboli PJ, Vaughan-Sarrazin MS, Cai X, Wolf BR, et al. Clinical characteristics and outcomes of Medicare patients undergoing total hip arthroplasty, 19912008. JAMA 2011;305:1560-7.

27. Bernatz JT, Tueting JL, Anderson PA. Thirty-day readmission rates in orthopedics: a systematic review and meta-analysis. PLoS One 2015;10:e0123593.

28. Bohm ER, Dunbar MJ, Frood JJ, Johnson TM, Morris KA. Rehospitalizations, early revisions, infections, and hospital resource use in the first year after hip and knee arthroplasties. J Arthroplasty 2012;27:232-7.e1.

29. Singh JA, Inacio MC, Namba RS, Paxton EW. Rheumatoid arthritis is associated with higher ninety-day hospital readmission rates compared to osteoarthritis after hip or knee arthroplasty: a cohort study. Arthritis Care Res (Hoboken) 2015;67:718-24.

30. Kheir MM, Clement RC, Derman PB, Flynn DN, Speck RM, Levin LS, et al. Are there identifiable risk factors and causes associated with unplanned readmissions following total knee arthroplasty? J Arthroplasty 2014;29:2192-6.

31. Helm JE, Alaeddini A, Stauffer JM, Bretthauer KM, Skolarus TA. Reducing hospital readmissions by integrating empirical prediction with resource optimization. Prod Oper Manag 2016;25:233-57.

32. Glance LG, Kellermann AL, Osler TM, Li Y, Mukamel DB, Lustik SJ, et al. Hospital readmission after noncardiac surgery: the role of major complications. JAMA Surg 2014;149:439-45.

33. Morris MS, Deierhoi RJ, Richman JS, Altom LK, Hawn MT. The relationship between timing of surgical complications and hospital readmission. JAMA Surg 2014;149:348-54.

34. Parvizi J, Mui A, Purtill JJ, Sharkey PF, Hozack WJ, Rothman RH, et al. Total joint arthroplasty: When do fatal or near-fatal complications occur? J Bone Joint Surg Am 2007;89:27-32.

35. Gandhi R, Petruccelli D, Devereaux PJ, Adili A, Hubmann $\mathrm{M}$, de Beer J. Incidence and timing of myocardial infarction after total joint arthroplasty. J Arthroplasty 2006;21:874-7. 